\title{
Electrochemical and Corrosion Behavior of 316L Stainless Steel in a $\mathrm{CO}_{2}-\mathrm{SO}_{2}-\mathrm{H}_{2} \mathrm{O}$ Mixture
}

\author{
Yong Xiang ${ }^{1,2, *}$, Chen $\mathrm{Li}^{1,2}$, Zhengwei Long ${ }^{1,2}$, Canwen Zhang ${ }^{1}$, Zhongli Ji ${ }^{1,2}$ \\ ${ }^{1}$ College of Mechanical and Transportation Engineering, China University of Petroleum, Beijing \\ 102249, China \\ ${ }^{2}$ Beijing Key Laboratory of Process Fluid Filtration and Separation, China University of Petroleum, \\ Beijing 102249, China \\ *E-mail: xiangy@cup.edu.cn
}

doi: $10.20964 / 2018.04 .51$

Received: 15 December 2017 / Accepted: 10 February 2018 / Published: 6 March 2018

\begin{abstract}
Although steel corrosion in a $\mathrm{SO}_{2}$-containing atmospheric environment has been extensively investigated, its electrochemical behavior still needs to be addressed, especially when it coexists with $\mathrm{CO}_{2}$ in a carbon capture, utilization and storage system. In this work, electrochemical experiments with $316 \mathrm{~L}$ stainless steel corrosion in a $\mathrm{CO}_{2}$-saturated solution were conducted by adding different amounts of $\mathrm{SO}_{2}$ to a solution at $25{ }^{\circ} \mathrm{C}$ under different $\mathrm{pH}$ conditions. The effect of $\mathrm{SO}_{2}$ on the cathodic reactions of $316 \mathrm{~L}$ stainless steel corrosion in a $\mathrm{CO}_{2}$-saturated solution was investigated by electrochemical methods, including potentiodynamic sweep, linear polarization resistance and electrochemical impedance spectroscopy. The results showed that the presence of $\mathrm{SO}_{2}$ increased the cathodic limiting current and corrosion rates of $316 \mathrm{~L}$ stainless steel at the same $\mathrm{pH}$. There was a "second-wave" phenomenon that appeared before the second limiting current and this new "wave" was demonstrated to be related to the direct reduction of both hydrate of $\mathrm{SO}_{2}$ and bisulfite on the steel surface.
\end{abstract}

Keywords: CCUS; $\mathrm{CO}_{2} ; \mathrm{SO}_{2}$; cathodic reaction; 316L stainless steel

\section{FULL TEXT}

(C) 2018 The Authors. Published by ESG (www.electrochemsci.org). This article is an open access article distributed under the terms and conditions of the Creative Commons Attribution license (http://creativecommons.org/licenses/by/4.0/). 